\title{
Surgical Treatment of the Congenital Valvular and Subvalvular Aortic Stenosis
}

\author{
Ken-ichi Asano, M.D., Masahiko Washio, M.D., Kota Shrozaki, M.D., \\ Shoji Eguchi, M.D., and Makoto Tanaka, M.D.
}

\section{Summary}

Four surgical cases of the congenital aortic stenosis, that is, a case of the valvular stenosis, a case of the diaphragmatic subvalvular stenosis and 2 cases of the hypertrophic subaortic stenosis, were presented. In Japan, surgical experiences of both the valvular and the paravalvular aortic stenosis have been scarcely reported in the literature. The incidence of these lesions is about 1 per cent among all operated congenital heart diseases in the Department of the Thoracic and Cardiovascular Surgery of the Niigata University Hospital. Three of them were corrected surgically with success, and a case of the diffuse or idiopathic hypertrophic subaortic stenosis was limited to exploration because its severity was evaluated to be mild.

\section{Additional Indexing Words :}

Valvuler stenosis Subvalvular stenosis Hypertrophic subaortic stenosis

\begin{abstract}
A
LTHOUGH numerous cases of the congenital aortic stenosis have been reported in American and European literatures and the incidence of this lesion is even estimated 10 per cent among all congenital heart diseases, in Japan this anomaly is seldom encountered, and only 2 cases of the supravalvular $^{1,2)}$ and a case of the diaphragmatic subvalvular aortic stenosis, ${ }^{31}$ surgically corrected with success have been reported in Japanese literature.

The authors have recently experienced 4 cases, that is, a case of the valvular aortic stenosis, a case of the diaphragmatic subvalvular aortic stenosis and 2 cases of the hypertrophic subaortic stenosis. The purpose of this paper is to report these surgical experiences.
\end{abstract}

\section{Gase Reports}

Case 1. A 14-year-old boy, who was found to have a congenital heart disease at 6 years of age, complained palpitation and breathlessness on exercise. The pulse was regular and its rate was 84 per min. The blood pressure was $95 / 80 \mathrm{~mm}$.

From the Department of Thoracic and Cardiovascular Surgery, Faculty of Medicine, University of Niigata, Niigata.

Received for publication April 10, 1967. 


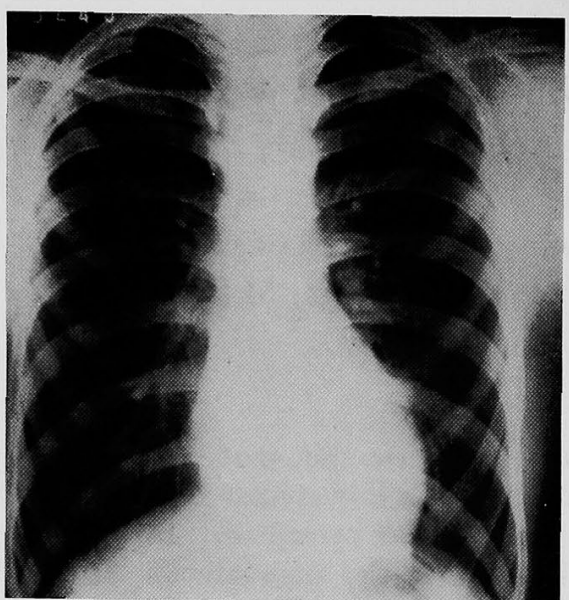

Case 1

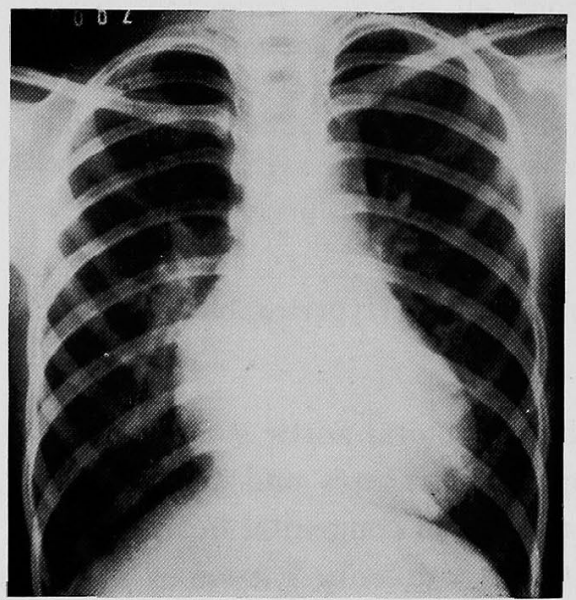

Case 3

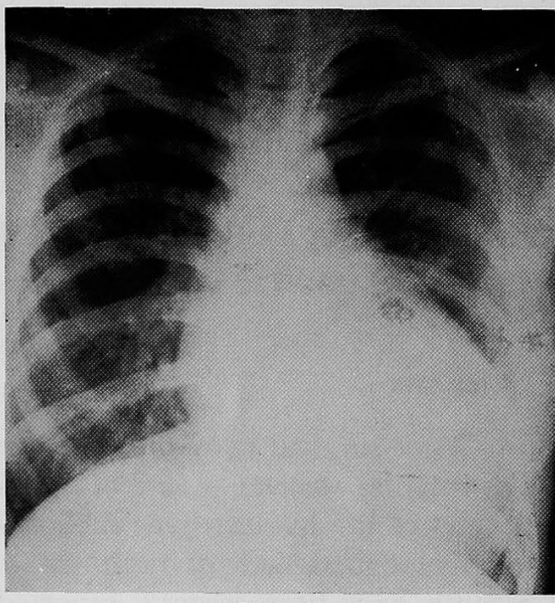

Case 2

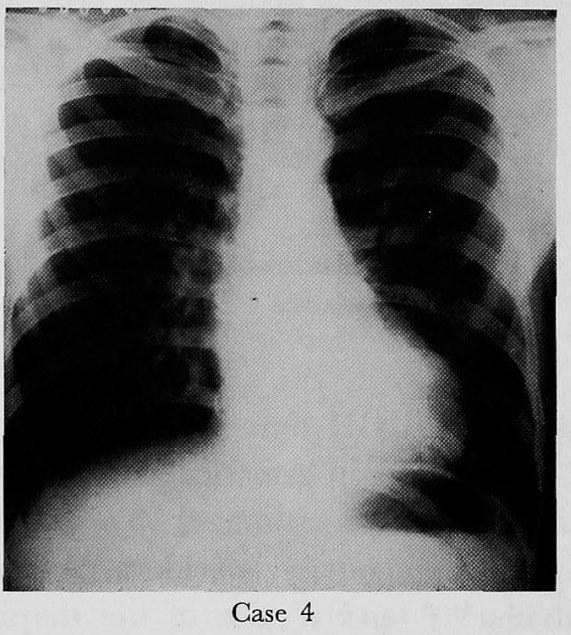

Case 4

Fig. 1. Chest X-ray films.

Hg. Chest examinations revealed neither deformity nor thrills, but a systolic ejection murmur (Grade 3/6) at 3-R and LSB, radiating to the right neck was auscultated. Hematologically the hemoglobin was $13.3 \mathrm{Gm} . / 100 \mathrm{ml}$., the red cell count was $453 \times$ $10^{4} / \mathrm{mm}^{3}$ and the hematocrit was 42 per cent. CRP was one plus positive and ASL-O was 166 Todd units. The chest X-ray film demonstrated neither cardiomegaly (GTR was 49.2\%) nor poststenotic aortic dilatation (Fig. 1). The electrocardiogram showed left ventricular hypertrophy with a depressed $S$ in $V_{6}$ (Fig. 2).

The left ventricular pressure measurement was performed by the Brock's direct transthoracic puncture method. Its pressure was $170 / 10 \mathrm{~mm} . \mathrm{Hg}$, and the simultaneous femoral arterial pressure was $100 / 60 \mathrm{~mm}$. $\mathrm{Hg}$ (Table I).

He was operated upon as the congenital aortic stenosis on March 1, 1966. The ascending aorta was not dilated but thrills were palpated on its wall. The aortic 

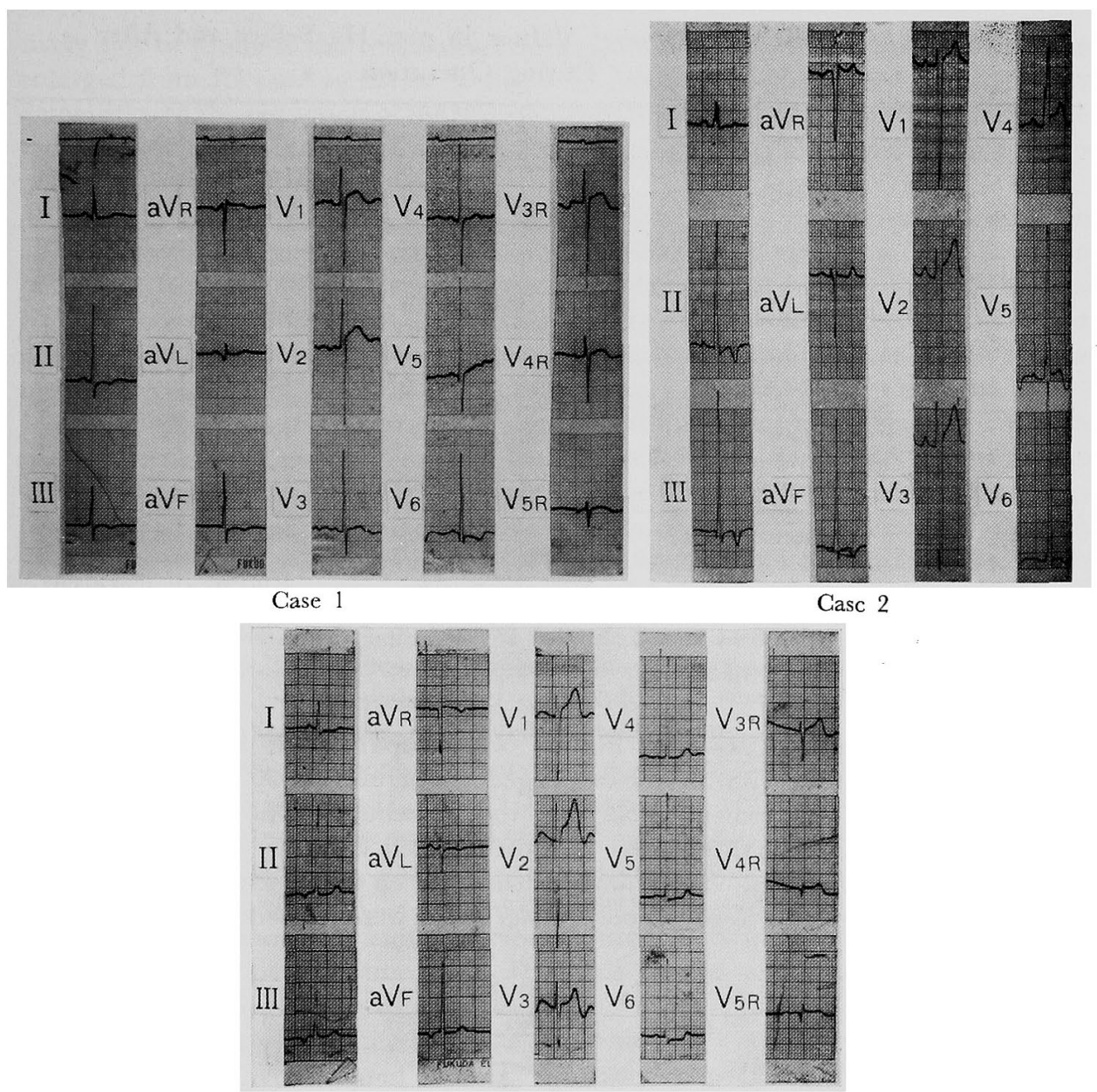

Clase 3

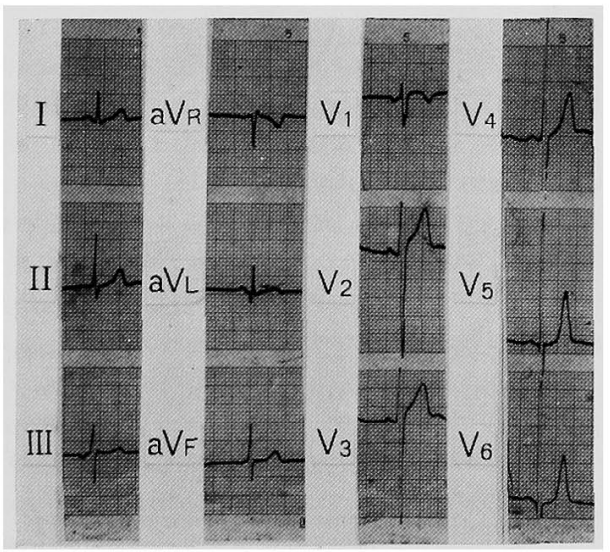

Case 4

Fig. 2. Electrocardiographic findings. 
Table I. Intracardiac Pressure Values in mm. $\mathrm{Hg}$ Before and After Procedure During Operation

\begin{tabular}{|c|c|c|c|c|c|}
\hline & & PA & RV & LV & $\mathrm{AO}$ \\
\hline \multirow[t]{2}{*}{1} & Before & & $65 / 25$ & $\begin{array}{c}(170 / 10) \\
190 / 20\end{array}$ & $\begin{array}{c}(100 / 60) \\
110 / 60\end{array}$ \\
\hline & After & & $50 / 15$ & $185 / 20$ & $130 / 95$ \\
\hline \multirow[t]{2}{*}{2} & Before & $\begin{array}{c}(28 / 5) \\
40 / 22\end{array}$ & $\begin{array}{c}(32 / 0) \\
50 / 5\end{array}$ & $220 / 16$ & $130 / 88$ \\
\hline & After & & $52 /-2$ & $130 / 4$ & $100 / 50$ \\
\hline \multirow{2}{*}{3} & Before & $52 / 16$ & $52 / 4$ & $120 / 5$ & $80 / 50$ \\
\hline & After & $50 / 30$ & $50 / 20$ & $110 / 20$ & $92 / 60$ \\
\hline \multirow{2}{*}{4} & Before & $36 / 0$ & $40 / 6$ & $98 / 8$ & $80 / 50$ \\
\hline & After & & & $160 / 12^{*}$ & $120 / 68^{*}$ \\
\hline
\end{tabular}

Note: 1) Value in parenthesis is one, recorded at the preoperative catheterization. 2 ) $*$ is the value, recorded after injection of "Alotec".

root was transversely incised with the aid of cardiopulmonary bypass. The flow rate was $1.8 \mathrm{~L} . / \mathrm{min} . / \mathrm{M}^{2} \mathrm{BSA}$ at the esophageal temperature of $30^{\circ} \mathrm{C}$. The coronary perfusion was not performed throughout the procedure. The aortic valve was stenotically bicuspidized with fusion of right and left coronary cusps and the enlarged non-coronary cusp. Two commissures between the noncoronary-right coronary cusps and the left coronary-noncoronary cusps were incised by $2 \mathrm{~mm}$. respec-

Case 1

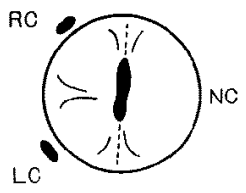

Case 2

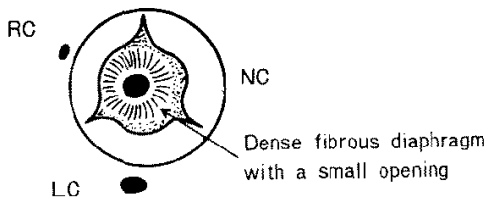

LC

Case 3
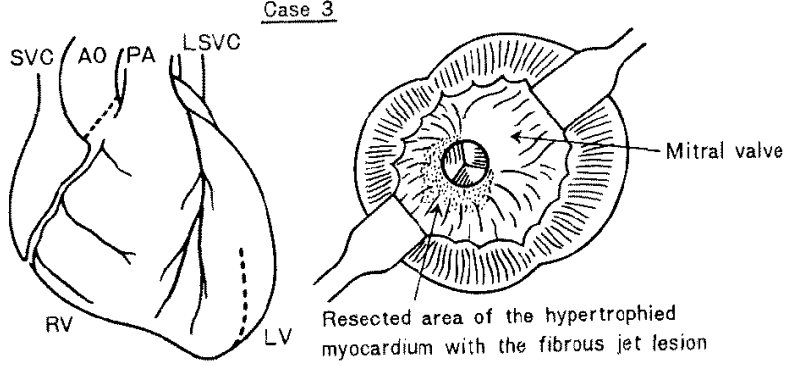

Fig. 3. 
tively not to produce the residual aortic insufficiency, and the valvular orifice was enlarged from $1.1 \mathrm{~cm}^{2}$ to $2.2 \mathrm{~cm} .{ }^{2}$ (Fig. 3). Intraoperative pressure measurements demonstrated the reduction of the systolic pressure gradient between the left ventricle and the aorta (Table I). The total cardiopulmonary bypass lasted $25 \mathrm{~min}$. His postoperative course was uneventful.

Case 2. A 15-year-old girl, who was found to have a congenital heart disease at 3 months of age, complained sensitiviness to cold and dyspnea on exercise. The pulse was regular and its rate was 76 per min. The blood pressure was $95 / 70 \mathrm{~mm}$. $\mathrm{Hg}$ at the left arm and $118 / 60 \mathrm{~mm} . \mathrm{Hg}$ at the right arm. Chest examinations revealed no deformity, but a systolic ejection murmur (Grade 4/6) at 2-RSB radiating to the neck was auscultated. Thrills were palpable. The hemoglobin was $14.6 \mathrm{Gm} . / 100 \mathrm{ml}$., the red cell count was $529 \times 10^{4} / \mathrm{mm}^{3}$ and the hematocrit was 45 per cent. All serological examinations, including CRP, ASL-O and RA were negative. The liver was palpable one finger breadth below the right costal margin, but function tests of liver and kidney revealed no abnormality. The chest X-ray film demonstrated marked cardiomegaly (GTR was $63.4 \%$ ), but the poststenotic dilatation was not found (Fig. 1). The electrocardiogram revealed severe left ventricular hypertrophy with a deep $\mathrm{S}$ in $\mathrm{V}_{1}$ and a depressed ST-segment and a inverted $\mathrm{T}$ wave in $\mathrm{V}_{5-6}$ (Fig. 2). The retrograde aortic catheter could not be inserted into the left ventricle, but the right heart catheterization revealed neither intracardiac pressure abnormality nor significant left-to-right shunt.

The operation was performed under the clinical diagnosis of the congenital aortic stenosis on February 16, 1967. The ascending aorta was slightly dilated and thrills were palpated on its wall. The aortic root was transversely incised under cardiopulmonary bypass. The flow rate was $2.1 \mathrm{~L} . / \mathrm{min} . / \mathrm{M}^{2} \mathrm{BSA}$ and the esophageal temperature was $31^{\circ} \mathrm{C}$. The aortic valve was not stenotic, but a fibrous dense diaphragm with a small opening was found through the aortic orifice pushing aside the aortic valve by retractors (Fig. 3). This fibrous tissue was excised and the opening was enlarged from $0.3 \mathrm{~cm} .{ }^{2}$ to $3.3 \mathrm{~cm} .{ }^{2}$ The left coronary artery perfusion by the controlled gravity method was performed only during closure of the aortic wall. The total bypass lasted $39 \mathrm{~min}$. Intracardiac pressure measurements during operation revealed the marked reduction of the left ventricular systolic pressure and the systolic pressure gradient between the left ventricle and the left radial artery (Table I). Her postoperative course was uneventful.

Case 3. A 12-year-old girl, who had been sensitive to cold and had been diagnosed as a congenital heart disease since 7 years old, was retarded in growth but without any manifest symptoms. The pulse was regular and its rate was 84 per min. The blood pressure was $93 / 58 \mathrm{~mm} . \mathrm{Hg}$ at the left arm and $88 / 50 \mathrm{~mm} . \mathrm{Hg}$ at the right arm. Chest examinations revealed neither deformity nor thrills, but a systolic ejection murmur (Grade 3/6) was heard at 4-LSB, radiating via 2-RSB to the right neck. The chest X-ray film demonstrated moderate cardiomegaly (CTR was $59.6 \%$ ) and a suspected remnant left superior vena cava (Fig. 1). The electrocardiogram showed severe left ventricular hypertrophy with a depressed ST segment in $\mathrm{V}_{5-6}$ (Fig. 2). In laboratory examinations, the hemoglobin was $10.3 \mathrm{Gm} . / 100 \mathrm{ml}$, the red cell count was $492 \times 10^{4} / \mathrm{mm}^{3}$ and the hematocrit was 34 per cent. GRP, ASL-O and RA were negative and function tests of liver and kidney were within normal limit. The retrograde left heart catheterization was not successful, although the serial aortograms revealed the moderately dilated aortic sinus and the small 
aortic root. The supravalvular aortic stenosis was preoperatively suspected.

The operation was carried out on June 30, 1966, utilizing cardiopulmonary bypass with moderate hypothermia. The flow rate was $1.8 \mathrm{~L} . / \mathrm{min} . / \mathrm{M} .^{2} \mathrm{BSA}$. The ascending aorta was unexpectedly constricted inspite of presence of thrills on its wall. The intracardiac digital examination through the right appendage revealed no abnormality in the right-sided heart. Intracardiac pressure measurements demonstrated that left ventricle was $120 / 5 \mathrm{~mm}$. $\mathrm{Hg}$ and the aorta was $80 /$ $50 \mathrm{~mm} . \mathrm{Hg}$, and the aortic stenosis rather than the supravalvular type was diagnosed. After occlusion of superior and inferior venae cavae, the right atrium was incised in order to insert the catheter into the left superior vena cava. The aortic root was obliquely incised, and both supravalvular and valvular aortic stenosis were not found. An operator's index finger could not be inserted into the left ventricular chamber and the localized subaortic hypertrophic stenosis was confirmed. Because the transvalvular resection of the hypertrophic mass was difficult, the left ventricular longitudinal incision near the apex was added and through this opening the stenotic mass including the fibrous jet lesion and the hypertrophied myocardium was deliverately excised in small quantities and additional dilatation of the outflow tract by the index finger was performed (Fig. 3). During this procedure, the continuous left coronary perfusion by the controlled gravity method was carried out and the total bypass time was $122 \mathrm{~min}$. Intraoperative pressure measurements revealed the effective decrease of the systolic pressure gradient between the left ventricle and the aorta (Table I). Her postoperative course was uneventful, and the electrocardiogram 8 months after the operation was improved to normal.

Case 4. A 12-year-old boy, who was found to have a congenital heart disease since at birth, was subjected to physical restriction under the diagnosis of the ventricular septal defect inspite of no severe symptoms. The pulse was regular and its rate was 64 per min. The blood pressure was $124 / 72 \mathrm{~mm}$. $\mathrm{Hg}$. Chest examinations revealved a systolic murmur (Grade 3/6) at 4-LSB without its radiation to the neck, the single 2 nd sound and the accentuated $P_{2}$. There were no chest deformity and thrills palpable. The chest X-ray film demonstrated the left ventricular enlargement and the slightly protruded aortic knob, but increased pulmonary vascularizations were not found. GTR was 50.6 per cent (Fig. 1). The electrocardiogram showed moderate left ventricular hypertrophy with a slight depression of ST-segment in $V_{B}$ (Fig. 2). Hematologically the hemoglobin was $14.0 \mathrm{Gm} . / 100 \mathrm{ml}$., the red cell count was $512 \times 10^{4} / \mathrm{mm}^{3}$ and the hematocrit was 44 per cent. CRP, ASL-O and RA were all negative. The mild-degree ventricular septal defect was diagnosed clinically, and he was operated upon on July 21, 1966.

On exploration of the heart, unexpectedly, neither thrills were palpable on the right-sided heart, nor the regurgitant jet was detected by the intracardiac digital examination through the right appendage, but slight thrills were palpated on the ascending aortic wall. Therefore, under the controlled respiration by the room air, intracardiac pressure and blood gas measurements were performed on the operative table. However, the left-to-right shunt in the right-sided heart chamber and the systolic pressure gradient between the left ventricle and the aorta were not found. Finally, when a small dose of "Alotec" (1-2-isopropylum ethanol sulfate) was injected intravenously, the left ventricular pressure markedly rose to $160 / 0 \mathrm{~mm}$. $\mathrm{Hg}$, and the rise of the aortic pressure was slight $(120 / 92 \mathrm{~mm} . \mathrm{Hg})$ (Table I). Succeedingly an operator's little finger was inserted through the left ventricular apex and the 
diffuse myocardial hypertrophy of the left ventricle without any localized protrusion was noticed. According to the above mentioned findings indicating the slight degree of the diffuse or idiopathic hypertrophic subaortic stenosis, the operative procedure was limited to exploration. His postoperative course was uneventful and stable.

\section{Discussion}

In Japan, surgical experiences of the valvular or the paravalvular aortic stenosis have been scarcely reported in the literature. The incidence of these lesions in the Department of the Thoracic and Cardiovascular Surgery of the Niigata University Hospital is 0.97 per cent among all operated congenital heart diseases. Because there are numerous articles about this subject, the authors do not intend to describe the incidence, the pathological classification, the clinical features and the surgical treatment, etc. But, clinical clue to detect the congenital aortic stenosis is in routine practice to put the stethoscope on the right neck. Moreover, the careful auscultation must be practiced when no thrills were palpable on the anterior chest wall when a systolic murmur is heard at the cardiac base. The clinical differential diagnosis from the ventricular septal defect seems frequently difficult when the radiation of systolic murmur to the neck was not found, and the ventricular septal defect must be excluded by the routinely performed right heart catheterization.

The diffuse or idiopathic hypertrophic subaortic stenosis is very interesting both hemodynamically and surgically, but today the mild case without any complaints like our case must be excluded from the surgical indication since the ever effective operative procedure has been not yet established.

\section{REFERENCES}

1. Taguchi, K., Kurihara, Y., Fujimura, K., Hirano, K., and Ashicate, I.: Operation 17: 1072, 1963 (in Japanese).

2. Sakakibara, S., Kishi, K., Tanaka, T., Takao, A., Fujikura, I., Nishida, H., Wada, H., and Ando, M.: Jap. J. Thorac. Surg. 19:915, 1966 (in Japanese).

3. Ishiai, S., Komoto, Y., Hamamatsu, H., and Fujiwara, T.: Jap. J. Thorac. Surg. 15: 662, 1962 (in Japanese). 